\title{
Hookworm diagnosed during colonoscopy and terminal ileum intubation
}

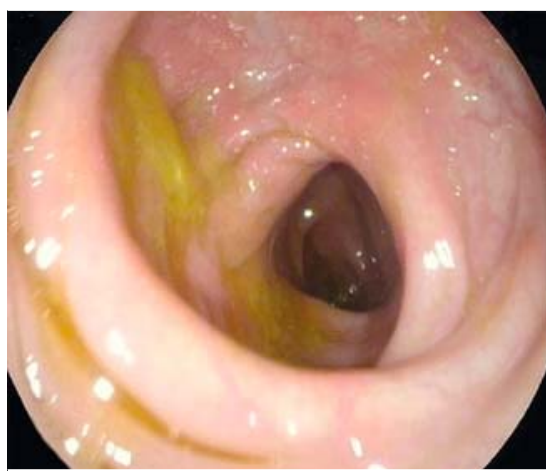

- Fig. 1 Mild erythema in the mid transverse colon of a 38-year-old patient with bloating and nonspecific abdominal pain.

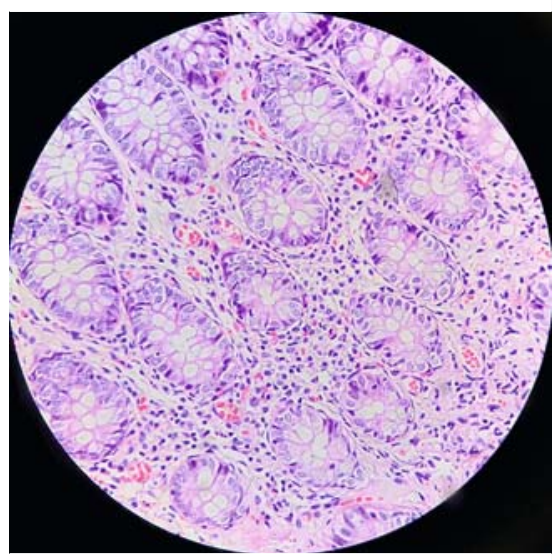

- Fig. 2 Eosinophilic infiltration of mucosa in the transverse colon.

A 38-year-old man attended the gastrointestinal outpatient clinic with a 3-month history of bloating, nonspecific abdominal pain, and irregular bowel habit. His laboratory findings included the following: hemoglobin $12.1 \mathrm{~g} / \mathrm{dL}$, mean corpuscular volume $81 \mathrm{fL}$, white blood cell count $5.4 \times 10^{9} / \mathrm{L}$, platelet count $245 \times 10^{9} / \mathrm{L}$, stool exam normal. Based on the recent onset of his complaints and lack of response to symptomatic management, he was referred for colonoscopy. Apart from mild erythema in the transverse colon ( Fig. 1), colonoscopy showed no significant findings, but at terminal ileum intubation multiple hookworms were seen

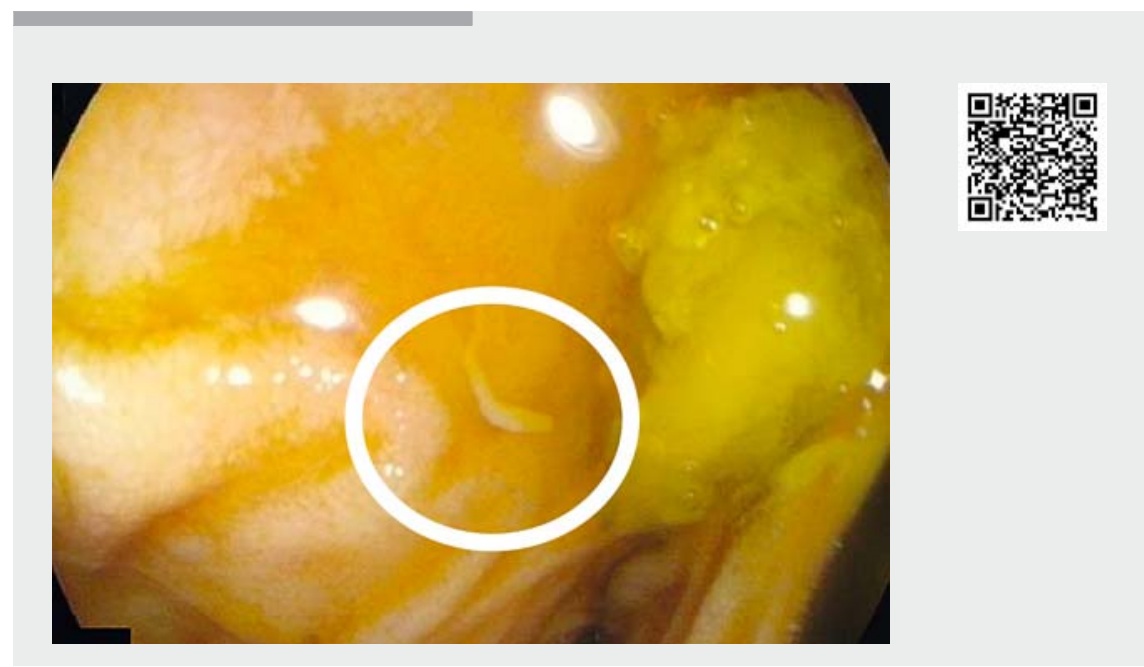

Video 1 Hookworm attached to mucosa of the terminal ileum.

attached to the mucosa ( $\vee$ Video 1 ). During withdrawal of the scope, several biopsy samples were obtained from the mid transverse colon. The pathologist reported mild to moderate infiltration of eosinophils in the colonic mucosa ( $>$ Fig. 2 ). Treatment with albendazole $400 \mathrm{mg}$ twice daily was started, and 2 weeks later all of the patient's symptoms had disappeared.

Human hookworm infections are mainly caused by two anthroponotic species, Necator americanus and Ancylostoma duodenale, which are transmitted through contact with contaminated soil [1]. Infected individuals are usually asymptomatic or present with chronic occult bleeding, and in developing countries, especially in the tropics, worm infestation should be considered an important cause of obscure acute gastrointestinal bleeding [2]. Hookworms rarely cause intermittent or chronic diarrhea, and they are known as parasites of the small intestine [3]. Our patient's main complaint was bloating and irregular bowel habit without any history of blood loss. His parasites were found during terminal ileum intubation, and biopsy from normal-looking mucosa revealed mucosal eosinophilia.
The most commonly used drugs for treatment of hookworms are mebendazole and albendazole [4]. Three consecutive daily doses of either drug improve the symptoms [5].

Hookworm infection can present as bloating and nonspecific abdominal pain. This case further emphasizes the importance of terminal ileum intubation and of lowering the threshold for obtaining tissue biopsy during colonoscopy.

Endoscopy_UCTN_Code_CCL_1AD_2AZ

\section{Competing interests}

The authors declare that they have no conflict of interest.

The authors

Pezhman Alavinejad ${ }^{1}$, Amir Hossein Sina ${ }^{2}$, Mehrdad Nikfam ${ }^{1}$

1 Alimentary Tract Research Center, Ahvaz Imam Hospital, Ahvaz Jundishapur University of Medical Sciences, Ahvaz, Iran

2 Narges Medical Genetics Laboratory, Ahvaz, Iran 
Corresponding author

\section{Pezhman Alavinejad, MD}

Department of Gastroenterology, Ahvaz Jundishapur University of Medical Sciences, Ahvaz, Iran

pezhmanalavinejad@gmail.com

\section{References}

[1] Hotez JM, Brooker P], Bethony S et al. Hookworm infection. N Engl J Med 2004; 351: 799-807

[2] Sharma BC, Bhasin DK, Bhatti HS et al. Gastrointestinal bleeding due to worm infestation, with negative upper gastrointestinal endoscopy findings: impact of enteroscopy. Endoscopy 2000; 32: 314-316

[3] Deesomsak M, Sawanyawisuth K, Prachayakul V. An unusual cause of chronic diarrhoea. Tropical Biomed 2014; 31: 187-189
[4] Keiser ], Utzinger ]. Efficacy of current drugs against soil-transmitted helminth infections: systematic review and meta-analysis. Jama 2008; 299: 1937-1948

[5] Steinmann P, Utzinger ], Du ZW et al. Efficacy of single-dose and triple-dose albendazole and mebendazole against soil-transmitted helminths and Taenia spp.: a randomized controlled trial. PloS One 2011; 6: e25003

\section{Bibliography}

Endoscopy 2021; 53: E33-E34

DOI 10.1055/a-1173-8265

ISSN 0013-726X

published online 29.5.2020

(c) 2020. Thieme. All rights reserved.

Georg Thieme Verlag KG, Rüdigerstraße 14,

70469 Stuttgart, Germany
ENDOSCOPY E-VIDEOS

https://eref.thieme.de/e-videos

回局 Endoscopy E-Videos is a free access online section, reporting 田: on interesting cases and new techniques in gastroenterological endoscopy. All papers include a high quality video and all contributions are freely accessible online.

This section has its own submission website at

https://mc.manuscriptcentral.com/e-videos 